\title{
Individualised medicine from the perspectives of patients using complementary therapies: a meta-ethnography approach
}

\author{
Brigitte Franzel", Martina Schwiegershausen, Peter Heusser and Bettina Berger
}

\begin{abstract}
Background: Personalised (or individualised) medicine in the days of genetic research refers to molecular biologic specifications in individuals and not to a response to individual patient needs in the sense of person-centred medicine. Studies suggest that patients often wish for authentically person-centred care and personal physicianpatient interactions, and that they therefore choose Complementary and Alternative medicine (CAM) as a possibility to complement standard care and ensure a patient-centred approach. Therefore, to build on the findings documented in these qualitative studies, we investigated the various concepts of individualised medicine inherent in patients' reasons for using CAM.

Methods: We used the technique of meta-ethnography, following a three-stage approach: (1) A comprehensive systematic literature search of 67 electronic databases and appraisal of eligible qualitative studies related to patients' reasons for seeking CAM was carried out. Eligibility for inclusion was determined using defined criteria. (2) A metaethnographic study was conducted according to Noblit and Hare's method for translating key themes in patients' reasons for using CAM. (3) A line-of-argument approach was used to synthesize and interpret key concepts associated with patients' reasoning regarding individualized medicine.
\end{abstract}

Results: (1) Of a total of 9,578 citations screened, 38 studies were appraised with a quality assessment checklist and a total of 30 publications were included in the study. (2) Reasons for CAM use evolved following a reciprocal translation. (3) The line-of-argument interpretations of patients' concepts of individualised medicine that emerged based on the findings of our multidisciplinary research team were "personal growth", "holism", "alliance", "integrative care", "self-activation" and "wellbeing".

Conclusions: The results of this meta-ethnographic study demonstrate that patients' notions of individualised medicine differ from the current idea of personalised genetic medicine. Our study shows that the "personal" patients' needs are not identified with a specific high-risk group or with a unique genetic profile in the sense of genome-based "personalised" or "individualised" medicine. Thus, the concept of individualised medicine should include the humanistic approach of individualisation as expressed in concepts such as "personal growth", "holistic" or "integrative care", doctor-patient "alliance", "self-activation" and "wellbeing" needs. This should also be considered in research projects and the allocation of healthcare resources.

Keywords: CAM, Qualitative studies, Meta-ethnography, Person-centred medicine, Individualised medicine, Personalised medicine

\footnotetext{
* Correspondence: brigitte.franzel@gmx.de

Center for Integrative Medicine, Faculty of Health, University of Witten/

Herdecke, Gerhard Kienle Weg 4, D-58313, Herdecke, Germany
} 


\section{Background}

Rather than referring to "individualised medicine" focusing on individualised care tailored to patient needs, the concept of "personalised medicine" in today's age of genetic research denotes the molecular biologic specification of individuals [1]. Current statements on personalised or individualised medicine appear mainly in the context of research and academic medicine, politics and economics. In recent years, individualised medicine has become a major research challenge, as clinicians and researchers have sought to discover more specific and individually tailored diagnostic tools and treatments for managing cancer, diabetes, and other common medical conditions [2]. Complementing this increase in genetic and molecular biological knowledge a clear trend has arisen towards genome-based individualised medicine; such genomicsassociated discoveries have opened up vast options for health care systems with regard to patient management. The German Bundestag's recent report on the future of "individualised medicine in the healthcare system" sought to assess the current state of health-related science and technology and the possible developments and implication associated with individualised medicine for medical care, health insurance and companies [2,3]. Therein five concepts of individualisation were presented: (1) individual biomarker-based stratification, (2) genomebased individual health-related characteristics, (3) genetic biomarkers, (4) individual disease risks and (5) differential intervention offerings and unique therapeutic items. As a further delineation, but also as an assignment by definition, "speaking medicine" (i.e. doctor-patient interaction) was attributed to the holistic medical approaches of the Complementary and Alternative medicine (CAM) [3].

However, the question has so far remained unanswered as to whether the current focus of research and academic medicine, politics and economics on molecular biologic specification can ameliorate the healthcare needs of patients in a balanced relation to the invested resources $[4,5]$. Furthermore, although the aims of innovations in healthcare systems include improved quality of life and other patient-specific goals, healthcare providers often neglect sufficiently to discuss with patients realistic expectations regarding such aims. A research gap has been identified in "that the real target audience for individualised medicine so far has hardly been questioned about their preferences" [3].

Patients' concerns about this lack of individualised attention and open dialogue have been borne out in a number of reviews suggesting that patients often turn to Complementary and Alternative medicine (CAM) because they feel that the traditional healthcare system does not provide adequate patient-centred care or individualised physician-patient interactions, or because they are seeking more holistic or integrative forms of care [6-8]. The published reviews about reasons for CAM use analyse quantitative studies; at present there is no meta-synthesis of qualitative studies available.

Qualitative studies are applied when methods are needed to understand patients' subjective experiences and perceptions of healthcare [9-11]. As the nature of clinical knowledge based on quantitative research methods and statistical analysis can be somewhat limited when individual or subjective phenomena, contexts of illness or health, or patients specific individual needs are to be investigated, qualitative methods provide a more thorough approach for describing personal human behaviour and needs; this is also true for the study of CAM $[12,13]$.

Since primary qualitative studies sometimes reveal that concepts of person-centred care are part of the common expectation of patients seeking CAM practitioners [14], it is reasonable to expect that the accumulated knowledge provided by qualitative studies can provide an indepth understanding as to the concepts, ideas, perceptions, views and expectations of individualised medicine patients have who turn to CAM. For this reason, we decided to explore patients' views about individualised care by analysing their reasons for seeking CAM and subsequently extract, synthesise and interpret corresponding content from primary qualitative investigations in a meta-ethnographic study.

The goal of the project was to describe the concepts, expectations and perceptions of individualised medicine inherent in patients' reasons for using CAM, as documented in qualitative studies. To our knowledge, ours is the first publication to address this important research.

\section{Methods}

For this study, the method of meta-ethnography following the style of Noblit and Hare [15] was chosen to collect and analyse the essential knowledge of patients' reasons for CAM use and to synthesise and interpret patients' concepts of individualised medicine. A metaethnography, a form "pooling" findings of qualitative research, is a meta-analysis with a comparative textual analysis of published qualitative field studies [15]. There remains controversy as to which meta-synthesis method can be best used for diverse sorts of qualitative research projects such as the one described here. In this case, from various methods of meta-synthesis, we determined the meta-ethnography with its interpretive orientation, to be the best approach. Because patients' concepts, expectations or perceptions of individualised medicine were not readily available in primary studies at the time the research question was raised, we collected and analysed in a meta-ethnography patients' previously explored reasons for CAM use, and subsequently interpreted patients' concepts of individualised medicine. 
The research project included three major sequences (1) a systematic literature search of 67 electronic databases and the subsequent appraisal of selected publications of qualitative studies investigating patients' reasons for seeking CAM therapies, with inclusion eligibility determined using defined criteria (2) a conduction of a metaethnographic study following Noblit and Hare's [15] method to translate the key concepts of why patients use CAM; and (3) a line-of-argument approach for the synthesis and interpretation of patients' concepts of individualised medicine.

Following Noblit and Hare, our meta-ethnographic method included seven phases that overlapped and were repeated as the synthesis proceeded (Table 1).

\section{Results}

In the first sequence of the research project a total of 9,578 relevant articles were found, of which 3,615 were screened on the basis of abstracts and titles. Sixty-three full publications were analysed according to the predefined inclusion and exclusion criteria (Table 1). Of these 63 papers, a total of 25 publications were excluded after full text analysis and 38 publications were appraised with a quality assessment checklist. An additional eight publications were excluded following the quality assessment performed by two members of the research team working independently Further details about the literature search results are listed in the Additional file 2. The remaining 30 studies that we synthesised in our meta-ethnography originated mostly in the United States, the United Kingdom or Australia. The majority of these 30 studies consisted of studies of cancer patients or of patients with chronic diseases.

Characteristics of the studies included in the metaethnography are presented in Table 2. Of the 30 studies, 27 studies reported results of patients using various CAM modalities. Two of the studies we examined reported the use of meditation and prayer, and one study reported the use of body-based therapies (e.g., massage therapy). Most studies used a qualitative descriptive design and collected data using semi-structured interviews. Study themes were determined to be roughly similar, which Noblit and Hare expressed as "reciprocal" [15].

The reciprocal translation of reasons for CAM use, representing the second sequence of the research project, resulted in the following secondary-order themes: "time", "holism", "tailored care", "teamwork and equal relationship", "new avenues", "facilitating transformative effect", "support for self-healing power", "gentle and natural treatment", "less side effects", "autonomy and active control", "dimensions of wellbeing" and "accessibility and legitimization". The translated secondaryorder themes were the base for the line-of argument synthesis and the interpretation of patients' concepts of individualised medicine.
The third sequence of the research project was a "line of argument" synthesis and a higher-order interpretation from the reciprocal translation.

The six third-order concepts interpreted from the data are shown in Figure 1. The synthesis indicates that patients' value individualised medicine in terms of a humanistic approach, expressing the wish for an opportunity for "personal growth", a "holistic" form of care, ease of "self-activation" and "integrative care", a therapist- patient-"alliance" in the sense of establishing a healing relationship and "wellbeing". These concepts were not exclusive, and they overlapped in certain dimensions and sub-themes. The third-order concepts with the respective dimensions and sub-themes resulting from the "lines-of-argument synthesis" are presented below, with representative quotes from the original papers shown in Table 3.

\section{Personal growth}

Patients' concepts of "personal growth" stood for a personal transformation process that was expected to be induced or facilitated by the healthcare encounter and that encompassed a reassessment of disease and life histories, an identification of causes, an understanding of the disease, a re-evaluation of attitudes and priorities and a way to find a fitting philosophy of health and life. It also comprised an exploration and implementation of lifestyle changes, including elements such as increased body awareness and spirituality and an appreciation of nature and surroundings. This concept could be further subdivided into the four dimensions described below.

\section{Emotional disease handling}

Patients' motivation to seek individualised care and to visit CAM practitioners in the event of a serious or lifethreatening illness included the need to find time, space, opportunity and support to interpret and accept the illness emotionally. Here, the emotional and existential consternation caused by disease requires a thorough reassessment of one's personal situation [16-28].

\section{Biographical reassessment}

Serious illness often led to questions related to the meaning of life and disease. In their attempt to cope with such questions, people might seek person-centred care to receive assistance. Some patients understood their illness to be a teacher, which could lead to an effort to integrate their disease into the biographical context of their personality $[16,17,23,26,29,30]$.

\section{Correlation building}

The establishment of a correlation between physical symptoms and psychological, biographical and existential aspects was often understood by patients to be a 


\section{Table 1 Meta-ethnography steps according to Noblit and Hare [15]}

1 Getting started

2 Deciding what is relevant to the initial interest

3 Reading the studies

4 Determining how the studies are related

5 Translating the studies

6 Synthesizing translations
"Getting started" meant to define the objective or interest of the synthesis and the wording of the research question [2].

Sixty-seven databases, including medical, social science, psychology, nutrition and complementary medicine databases (i.e., API-on, CAMbase, CAM-QUEST, CINAHL, Cochrane Library, DIMDI, GREENPILOT, Heclinet, MedPilot, PubMed, Psyndex, PsynINFO, Sinbad, Somed), were searched for the Boolean terms "complementary and alternative medicine" OR "CAM" OR "complementary medicine" OR "alternative medicine" OR qualitative research" OR "qualitative studies" OR "interviews" OR "[exploratory OR grounded theory OR content analysis OR focus groups OR ethnography]" OR "reasons" OR "[concepts OR patient expectations OR motivation OR attitude to health OR patient communication OR health knowledge OR patient acceptance of health care OR patient participation OR physician-patient relations OR professional-patient relations]". The selection of these terms followed predetermined inclusion criteria and included qualitative research articles in English and German about reasons for CAM use from a patient perspective; all articles used in this analysis were published between 1980 and 2011. Exclusion criteria were qualitative studies with therapists, perspectives of teaching personnel, review and theory papers and articles devoted to study design and secondary analysis. A detailed description of the literature search and appraisal of the meta-ethnography will be published separately and is also mentioned in Additional file 1.

The studies were reviewed multiple times, while the findings of the individual qualitative studies were collected with extensive attention paid to the details in the articles and the key themes from each article were determined. Two members of the research team extracted the themes of the individual qualitative studies concerning patients' reasons for CAM usage and transferred them into a spreadsheet program as primary themes with their related explanations. The spreadsheet's columns contained the original authors and the key primary themes of reasons of patients seeking CAM, and the rows displayed the main explanations of the key themes or citations of the patients. Key themes were juxtaposed, with the most important interpretations of the authors focusing on concepts of individualised medicine (mostly in the discussion section of each article) in the last column; our team worked diligently to always keep in mind the research question, which was the expectation of patients related to individualised medicine. After the extraction of key themes with reasons of patients for CAM, the spreadsheet data and personal notes were discussed in regular meetings. This discussion revealed no important differences in the extracted data. The consolidated spreadsheet data were finally discussed with the entire research team.

For the syntheses, we had to determine how the individual studies were related. According to Noblit and Hare, the metaphors, concepts or constructs used for this purpose can be either (1) directly comparable as "reciprocal" translations; (2) stand in relative opposition to each other and are essentially "refutational"; or (3) present a "line-of-argument" rather than a reciprocal or refutational translation [15]. Here, "reciprocal" means that the studies can be combined such that one study can be presented in terms of another. "Reciprocal translation" involves uniting ideas and concepts from the original studies through a process of comparing across the studies. "Refutational" means that the studies can be set against one another such that the grounds for one study's refutation of another become visible. A "line-of-argument" synthesis ties the studies to one another and informs how the individual studies go beyond one another. At the end of this phase, the team assumed that the studies had re-occurring themes and that a "line-of-argument" analysis could be performed.

Translation in a meta-ethnography such as ours means comparing the metaphors and concepts in one article with the metaphors in others. We first arranged all papers chronologically and according to main indications. Thereafter, we compared the key themes from paper one with paper two, and the syntheses of these two papers with paper three, and so on. The translation respected the individual meaning and maintained the central metaphors in relation to the studies' other key metaphors. We translated our key themes across all articles in order to determine secondary key themes. All secondary key themes contributed reasoning behind why patients turn toward CAM. To perform the translation, the research team members worked with grids or hand cards. The relationship between the studies was indicated by drawing arrows, lines and bubbles or by clustering the hand cards. The emerging secondary key themes were transferred into the head line of a spreadsheet named "secondary key themes," and the applicable explanations were entered in the rows below, the themes were juxtaposed with the authors' main secondary interpretations from the discussion section of each article. We made analytical and reflexive notes during the translation to be prepared for the research group discussions.

The secondary key themes of the reciprocal translation were brought together by synthesizing them, starting from the identified secondary key themes and matching them with their respective patients' quotations of the primary studies. This process involved further re-readings of the original studies. The findings from the translation and the resulting spreadsheet data with secondary themes, explanations, interpretations and subthemes provided the foundation for a third order analysis. In this phase it was possible to re-conceptualize the findings, generating a new interpretation of the secondary-order themes. Each member of the research team independently developed an overarching mind-map and his or her own synthesis model that linked together the translated secondary key themes and authors' interpretations. These models were merged and discussed. In this phase we also used hand cards to pick apart the original explanations of the authors and subsequently put them together again in clusters. The clusters were compared to each other and classified, resulting in our new third-order concepts with dimensions and subthemes. This process was quite similar to standard primary qualitative research in terms of subjectivity of interpretation, and can be compared to a grounded theory approach that puts the similarities between studies into an interpretive order according to Noblit and Hare a "line of argument". The line of argument synthesis involved building up a picture of the whole from studies of its parts. Our interpretation aimed to develop a model to explain the overall concepts of patients about individualised medicine. 
refreshing exercise and could be perceived as personcentred care when the therapist provides the time and support for such discussion during the patient's visit $[16,17,19-24,26,29]$.

\section{Transformation}

The dimension of "transformation" reflected the possibility of personal development and a transformation of life; here, spiritual aspects seem to have become more relevant to patients reporting this dimension $[18,27,30,31]$. Patients appreciated an individualised approach in which they experienced support in inner development and which could have redefined their position from recipient (of treatment) to that of an explorer as their disease progressed [16,17,19-28]. With person-centred care patients felt empowered to develop new directions for improving their lives and lifestyle $[17,26,28,30]$.

\section{Holism}

The most common theme among all 30 studies was that of "holism". An individual approach was identified by CAM patients with a whole-person approach or a holistic approach. Instead of singular accounts for biomedical factors and isolated symptoms, patients reported that healthcare providers should take into consideration a wider range of factors or causes based on patients' opinions; these concerns included a variety of physical, psychological, spiritual, social and economic factors. Most patients acknowledged a wide concept of care, which opens up a greater number of dimensions than pure pharmacological treatment alone. This concept could be further subdivided into the two dimensions described below.

\section{Interdependencies of various treatments}

Holism reflects a comprehensive account of various levels of treatment. An individualised therapeutic approach could include various interactions with different medical specialties (e.g., surgeon, radiologist, general practitioner, psychologist, physiotherapist) and patient lifestyle aspects such as nutrition and exercise therapy [16-18,21,24,29,32-37].

\section{Respect of the whole person's state}

Patients acknowledged the importance of respect of their whole person's state, specifically referring to their desire for "an individual approach to be seen as a whole person" [19] rather than as composites of various biomedical attributes or isolated symptoms. Likewise, patients expected their therapists or physicians to approach them with a broad holistic world-view that integrated their physical, psychological, spiritual, social and economic dimensions of life.

\section{Integrative care}

Here, the concept of individualised medicine merges with integrative care. "Integrative care" refers to the patients' need for choosing amongst different treatments options, including treatment alternatives offered by conventional medicine $(\mathrm{COM})$ or combinations with CAM modalities. Patients had the desire for unique treatments that suited them personally, specifically through the option of selecting from a wide variety of modalities. Patients also wished to be explorers of their own health, capable of deciding for themselves among various CAM and COM modalities.

In the majority of cases, patients sought conventional treatment of their disease and appreciated the advances of modern medicine. However, they also wanted to have room for integrating into their care different models or healthcare options. This type of personal problemsolving or coping strategy using both complementary and conventional methods highlighted patients' willingness to seek out individualised opportunities. Over and above that, integrative care reflected patients' desire for better access to CAM therapies. This concept also represented patients' desire to discuss CAM use openly with COM providers without being dismissed or not taken seriously. The "integrative care" concept could be further subdivided into the dimensions described below.

\section{Tailored care}

Patients wanted their individual life and disease situation respected with a person-centred treatment approach which suited their specific personal needs in diagnosis, risk information and treatment. They appreciated providers' attempts to match appropriate practices and treatments to their unique problems, values, preferences and life circumstances, including conventional and complementary methods $[18,26,28,30,32,33]$.

\section{Integration of CAM and COM}

Patients perceived the establishment of a treatment protocol involving CAM as a highly individualised process [16,26,34-36]. However, patients also felt a responsibility to investigate for themselves potential side effects of recommended medications and treatments and through CAM they sought out treatment options that 
Table 2 Main criteria of included studies

\begin{tabular}{ll}
\hline Author: & Indication: \\
\hline Barrett et al. March 2000 [37] & Primary Car
\end{tabular}

Richardson et al. June 2004 [19] Primary Care

McCaffrey et al. July 2007 [29] Primary Care

Smith et al. May 2009 [32]

Grace et al. Sept. $2010[20$

Nichol et al. Feb. $2011[18$

la Cour et al. Dec 2008 [22

Richmond et al. May 2010 [45] Hepatitis C

Salamonsen et al. July 2010 [23] MS

Boon et al. Sept. 1999 [35]

Canales et al. Jan. 2003 [30]

Adler, Sept. $2009[25]$

Mulkins et al. March 2004 [27]

Steinsbekk et al. Febr. 2005 [38] Breast, Kidney, NHL,

Singh et al. Febr. 2005 [41] Prostate Cancer

Ribero et al. July 2006 [26]
Primary Care

Primary Care

Asthma

Rheumatic Disease

Breast Cancer

Breast Cancer

Breast Cancer

Breast, Colon, Prostate, Lung and

Throat Cancer Melanoma,

Colon.

27 patients, semi structured interviews

Data collection:

17 patients, semi structured in-depth interviews

204 patients, qualitative comments in health questionnaire

37 patients, focus group

19 patients, telephone focus group

22 patients, hermeneutic phenomenology: case studies, focus groups, key informant interviews

50 patients, semi-structured interviews with 22 adults and 28 children

15 patients, in-depth interviews

28 patients, semi-structured interviews

2 patients, of 12 qualitative interviews, issue (theme)-focused analysis on two cases

36 patients, focus groups

66 patients, focus groups

44 patients, semi structured interviews

11 patients, unstructured interviews

17 patients, semi structured interviews

Breast CA

6 patients, semi structured interviews
12 patients, focus groups
Setting:

Objective of each study:

Madison telephone listings, USA

To investigate know

To assess expectations of patients who use British NHS outpatient department CAM

To identify the motivations of people who Integrative care clinic in Cambridge, MA choose IM

To explore the attributes of the therapy New Zealand, clients of massage therapist encounter or practice

To understand the contribution integrative 3 integrative medicine clinics in Sydney, medicine can make to the quality of care Australia

To examine the family as a context for

Family Focus Clinics from Avon beliefs, decision-making about CAM sub-study, UK

To investigate why and how patients and parents of children use CAM

2 contrasting general practices, one in an affluent suburb one in a deprived inner city area, Bristol, UK

To investigate patients' experience and perceptions of CAM

patient-driven rheumatic disease societies, Denmark

To describe reasons for the use of mindbody medicine

liver clinic, tertiary healthcare facility in the United States

To obtain knowledge and understanding selection based on Registry of -exceptional Th patic their CAM use

To explore breast cancer survivors' perceptions and experiences of CAM

Specific reasons breast cancer surviviors reported for using CAM

To address older breast cancer patients' seeking of concurrent care Courses of Disease, Norway and Denmark

tertiary care allopathic medical centers, Canada

Vermont Mammography Registry, Vermont Canada

1593 breast cancer case listings provided by the Northern California Cancer Center

To identify features of the transformative 3 integrative care facilities in Vancouver experience among people who are

seeking integrative care

How patients experience consultations with CAM practitioners

outpatient clinic of oncology department at the university hospital, Norway

To compare the perceptions, beliefs, ideas part of a larger study, Hawaii Tumor and experiences that contribute to use CAM

To describe the attitudes, beliefs and Registry, USA

utilization of CAM

Komen Hawaii's Race for a Cure 
Table 2 Main criteria of included studies (Continued)

\begin{tabular}{|c|c|c|c|c|}
\hline Correa-Velez et al. Oct. 2005 [43] & Advanced cancer & 39 patients, semi structured interviews & $\begin{array}{l}\text { To identify in detail the reasons for using } \\
\text { CAM }\end{array}$ & $\begin{array}{l}\text { records of state cancer registry, } \\
\text { Queensland, Australia }\end{array}$ \\
\hline White et al. June 2006 [16] & Prostate cancer & $\begin{array}{l}29 \text { patients in-depth interviews + focus groups, } \\
\text { then secondary analysis from } 10 \text { of } 29 \text { patients } \\
\text { with spiritual practices }\end{array}$ & $\begin{array}{l}\text { To assess decision making by men who } \\
\text { use CAM }\end{array}$ & $\begin{array}{l}\text { men with a confirmed diagnosis of } \\
\text { prostate cancer in British Columbia and } \\
\text { Alberta, Canada }\end{array}$ \\
\hline Humpel et al. Sep. 2006 [39] & $\begin{array}{l}\text { Breast. Prostate, } \\
\text { colon, lung, liver } \\
\text { cancer }\end{array}$ & 19 patients, semi-structured in-depth interviews & $\begin{array}{l}\text { To gain a greater understanding of CAM } \\
\text { including motivations }\end{array}$ & $\begin{array}{l}\text { recruited via posters and study flyers } \\
\text { placed in med. waiting rooms, Australia }\end{array}$ \\
\hline Evans et al. Jan. 2007 [17] & $\begin{array}{l}\text { Prostate, lung } \\
\text { colorectal... }\end{array}$ & 34 patients, semi-structured interviews & $\begin{array}{l}\text { To investigate why men with cancer } \\
\text { choose to use CAM }\end{array}$ & $\begin{array}{l}\text { National Health Service (NHSJoncology } \\
\text { unit, NHS homeopathic outpatient, private } \\
\text { cancer charity }\end{array}$ \\
\hline Jones et al. March 2007 [36] & Prostate Cancer & 14 patients, semi-structured interviews & $\begin{array}{l}\text { To examine the cultural beliefs and } \\
\text { attitudes of the use of CAM }\end{array}$ & $\begin{array}{l}\text { Prostate cancer center in central Virginia + } \\
\text { referred by other participants, USA }\end{array}$ \\
\hline Broom August 2009 [28] & $\begin{array}{l}\text { multiple indication } \\
\text { cancer }\end{array}$ & 20 patients, semi-structured interviews & $\begin{array}{l}\text { To question how individuals make sense } \\
\text { of diverse treatment practices }\end{array}$ & two oncology departments in Australia \\
\hline Wanchai et al. July 2010 [31] & Breast Cancer & 9 patients, in-depth interviews & $\begin{array}{l}\text { What were the breast cancer survivors' } \\
\text { perceptions about CAM }\end{array}$ & $\begin{array}{l}\text { Cancer Center in the Midwestern region of } \\
\text { USA }\end{array}$ \\
\hline Foote-Ardah July 2003 [44] & HIV & $\begin{array}{l}62 \text { patients, qualitative interview, mostpart } \\
\text { conversational }\end{array}$ & $\begin{array}{l}\text { To aid understanding why people us CAM } \\
\text { for HIV }\end{array}$ & $\begin{array}{l}\text { Core group of persons withHIV from } \\
\text { personal networks and contacts made } \\
\text { through fieldwork, USA }\end{array}$ \\
\hline Chen et al. May 2009 [46] & HIV & 29 patients, semi-structured, in-depth interview & $\begin{array}{l}\text { To explore issues related to attitudes } \\
\text { toward CAM }\end{array}$ & Ditan hospital in Beijing, China \\
\hline McDonald et al. Oct. 2010 [40] & HIV & 9 patients, semi-structured interviews & $\begin{array}{l}\text { To examine the sociocultural meaning and } \\
\text { use of CAM }\end{array}$ & $\begin{array}{l}\text { Referrals from CAM practitioners at } \\
\text { community-based health service for } \\
\text { PLWHA, Melbourne, Australia }\end{array}$ \\
\hline Walter et al. May 2004 [33] & Menopause & $\begin{array}{l}36 \text { patients, focus groups, and } 4 \text { semi-structured } \\
\text { interviews }\end{array}$ & $\begin{array}{l}\text { To examine patients' perspectives of risk } \\
\text { communication }\end{array}$ & $\begin{array}{l}\text { two Cambridge practices from contrasting } \\
\text { parts of the city }\end{array}$ \\
\hline Patterson et al. Jan. 2008 [34] & Primary Care & $\begin{array}{l}13 \text { patients, semi-structured interviews, } \\
\text { adolescents } 15-20 \text { years }\end{array}$ & To explore adolescent CAM use & $\begin{array}{l}\text { Canadian College of Naturopathic } \\
\text { Medicine }\end{array}$ \\
\hline Conboy et al. 2008 [24] & Endometriosis & $\begin{array}{l}7 \text { patients, semi-structured interviews, adolescents } \\
13-22 \text { years }\end{array}$ & $\begin{array}{l}\text { To understand experiences of adolescents } \\
\text { with acupuncture }\end{array}$ & $\begin{array}{l}\text { primarilythrough the Division of } \\
\text { Gynecology of Children's Hospital, Boston, } \\
\text { MA }\end{array}$ \\
\hline
\end{tabular}




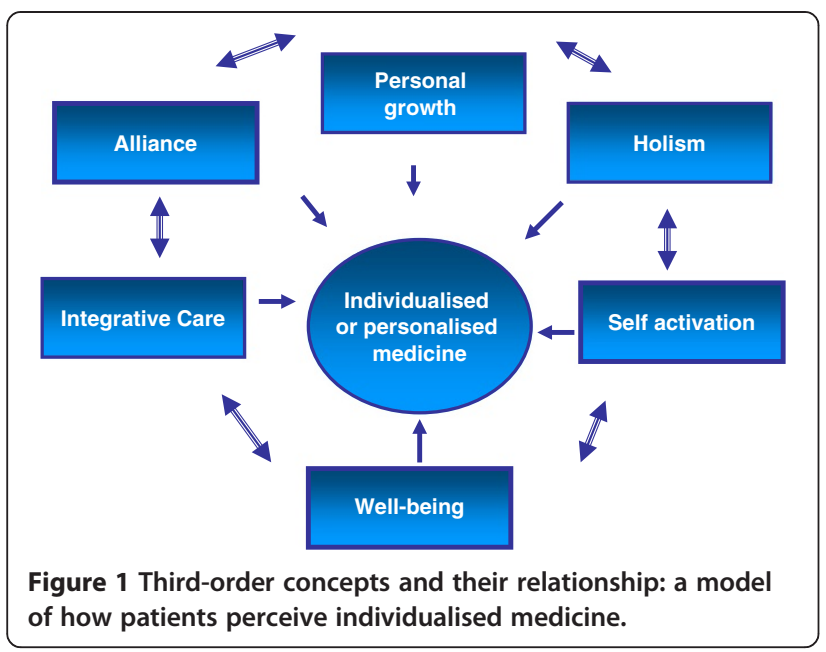

included fewer side effects, even when this interest was not shared by COM practitioners [29].

\section{Alliance}

One commonly identified expectation concerning individualised care expressed by patients who sought help from CAM therapists was the wish for a caring doctor-patient "alliance". This concept could be further subdivided into the two dimensions described below.

\section{Time}

A number of papers mentioned time as an important concept related to patients' perceptions of individualised care of CAM therapists. Specifically, patients wanted the undivided attention of their physicians, individual oneby-one time, the possibility to get additional appointments also in between regular visits, time to think about different treatment options seriously before making a decision and the feeling of the individual of being listened to $[19,32,33,37]$. Patients reported that they wished to have sufficient time for telling their personal history and for discussing health issues and for asking questions and obtaining appropriate explanations about disease and treatment options $[17,19,20,22,27,32,33,37,38]$.

\section{Healing relationship}

Patients expected respect from their physician $[18,25$, $33,37-39]$; they also asked for guidance $[19,24,32,34,36,40]$ and expressed a desire for an emotional bond with their care providers. The establishment of an effective doctorpatient "alliance" was directed towards a common goal; avoided paternalism and stereotypes; included an engaged and caring, empathetic and non-judgemental attitude on the side of the practitioner; and allowed for deeper patient understanding and empowerment [17-19,21,24-27,30,32, 34-36,39,40].

\section{Self-activation}

Patients' perspective on individualised medicine and their desire for "self-activation" represented the empowerment of "personal autonomy" and the "activation of the self-healing power" of the patient. Here, "personal autonomy" referred to the patient's conception of himself or herself as a victim (i.e., an ill person) as opposed to that of a person who has (re-)gained control over their treatment and health.

\section{Personal autonomy}

The dimension of gaining or regaining "personal autonomy" described patients' wish to be enabled through an individualised approach of "educational empowerment" to cope with and accept their own health and medical condition; take responsibility through active control for their own health; and become actively involved in decision making related to their condition $[17,22,23,27,38,41]$.

\section{Activation of self-healing power}

Several patients were persuaded that the activation of self-healing resources might have physiological, psychological, social, spiritual and quality-of-life benefits. Patients wanted to support their individual self-healing capacities and subsequently apply CAM to the standard treatment they received. This corresponds to the salutogenic idea [42] referring to approaches that support healing processes and wellbeing rather than fighting factors that cause disease. Correspondingly, patients wished for their health care providers to support, guide and coach them in developing and using self-healing techniques. Patients believed that individualised healthcare enforcing psychological processes which facilitated hope, positive expectations and feelings, relief of anxiety and anticipation of improvement could influence physiological processes and contribute to healing over and above pharmacologically mediated processes $[17,22,23,27,30,35$, $38,39,43]$.

\section{Wellbeing}

Patients expressed a basic need for health and appreciated the benefits of COM options for ameliorating and curing disease. However, patients at times experienced disappointment with COM and subsequently sought out alternative treatments. In the 30 studies synthesised here, patients turned to CAM and used alternatives mainly as individually tailored complements to standard medical treatments in a sense of "wellbeing" or quality of life. Here, "wellbeing" as a concept of individualised medicine reflected patients' wish for a physically and psychologically healthier feeling, emotional clarification and the relief from chronic symptoms. This concept could be further subdivided into the four dimensions described below. 
Table 3 Patients' concepts of individualised medicine

\section{Concepts \\ Sub-themes \\ Dimension}

Personal growth

Emotional disease handling

Biographical reassessment

Correlation building

Transformation

Interdependencies of various treatments

Respect of the whole person's state

Physical/Psychological holism

Social holism

Economical holism

\section{Quotations}

"I know that a cancer diagnosis is very dramatic. It changes your life forever. It makes you realize that you are mortal. It is only those people who have serious illnesses early in their life who are forced to stop and look at the fact that their life is so fragile. Nobody knows how much time you have left. Somewhere along the line I decided that I was going to use this as an opportunity to strengthen myself. I guess to take charge and get rid of all of this baggage I have been carrying around for the past 20 odd years or so" [27]. "I would say sometimes that a trauma like cancer is a blessing in disguise because it makes you realize to live each moment. Each moment is precious" [16].

"I don't sweat the small stuff anymore. Life is too short" [26]. "Maybe it [breast cancer] was just a blessing in disguise" [26]. "I mean, I changed my whole thinking. I was all into my career, and then I thought, do I want the kids to remember me as going out the door all the time or making chocolate chip cookies. And I totally reversed my thinking and stayed home for quite a few years, 3 or 4 years. I was more of a housewife and mother and all that. I don't regret that because I have three lovely children" [30].

"For the first time I felt like the various and seemingly disparate symptoms I was coming in with actually made sense to my healthcare provider and fit within a framework that that person understood, and also within a treatment model that that person understood, and then could be used to help make me better-which it is, and I $\mathrm{am}^{\prime}$ [29]. "Today I see that heavy mental pressure over time was what set the MS off, so preventing stress is my best medicine" [23]

"kind of like an abstract thing if you feel within yourself. How do you put that? I think I developed a stronger love for nature and the world around me - that kind of religious. Not, 'oh - God saved me.' I got more in tuned with my environment" [26]. [She judged the effectiveness of her therapy both in terms of symptom relief and support for a] "wider transformative journey" [26].

"It's time in the sense that they have got longer, but also they appear to be more interested. I like our GPs enormously and they're very talented individuals, but they don't have the time to talk... (homeopaths) look at the whole thing and they will say about diet, they will say what about your bedding, what about this, have you changed that?" [21]

"When I am feeling good, I think it's mental and it's physical and it's spiritual; it's all of it together" [29].

"I think it's healing emotionally, and when it healed you emotionally, it healed you physically" [31]

"And so preventative medicine, good, and I mean,...I think a very holistic view is good, and so if something helps you, even though it might seem rather mystic or mystical and you know, I think try it, although I am from a medical background and on one hand I'm thinking well, we need to see research and I work in a very research-based kind of environment, but I'm also a great believer in ... these other kinds of metaphysical or other kinds of therapy in any situation" [18]

"...। go already relaxed knowing that it is going to be a really useful hour, that she is interested not just in what I might be feeling or the things I think could need working on but interested in what has been going on in my life [She] knows a bit about my family, my background she knows where there might be problems areas outside of the body and this will help to create al feeling of trust and you can rely on it and rely on her. She does the things the body and this will help to create al feeling of trust and you can rely on it and rely on her. She does the things
like the glass of water and the personalised stuff and oils and what have you. It's just knowing that you will go away feeling that you've had both physical and emotional support" [32].

"It's not cheap, but I find I get benefit from it. So, I spend my money for something like this" [31].

"I think the biggest thing is that there is time. There is individual, one-on-one time" [29].

"I think the quality of listening is very important. My experience [with IM] has been that the doctors listen, and they make suggestions, and they listen back to how you feel about the suggestions. I am beginning to think that progressive medicine is finding a doctor who will listen" [29]. 
Integration of CAM and

COM

Accessibility

Legitimating alternatives

Self Activation

Personal autonomy

Empowerment through education and counselling

Active control

"You know in retrospect, it all looks so obvious. Now I see so many people who I feel are stagnant. It is a matter of being ready to embrace all of this chaos. This kind of self-involvement won't happen unless you are 100\% into it. It has been my own personal journey, and looking back, I don't think it would have happened any sooner. You truly need to be ready to take it on. Once you are I guess maybe things just start to happen" [27].

Time between and during visits

Wish for guidance counselling and

Emotional bonds

Tailored Care
"And every time I bring it up they blow it off. So I didn't get very far when I voiced my concerns." [37] "Yes, perhaps there's a difficulty now between being autocratic and being patronising, which must be quite though" [33].

"...it's a partnership, they'll look at what can you do as well" [32]. "To be advised and encouraged and to be made aware of how I can improve and help myself. To reach a better state of health and also mind" [19].

"My doctor here, she was funny, graceful, and loving and so she empowered me. We make decisions here as equals. She said, "Okay, so what do you want to do?" It was like I was the doctor. And so I told her some things and she said, "Yeah, okay, I agree with that." She was just so clear. She was always there for me too. In all of my care experiences here, it was like, "Tell me what is going on for you. Okay, well here are a few things you might want to try and this is what you can expect" [27].

"Because people are individuals, it could suit some people a lot better than like, mainstream medicine, and... some people may just be more comfortable with that.... think homeopathic medicines are a good...rather than just like the same thing for each different illness sort of thing, something unique for each person that suits them. I think. that works very well, so yeah" [18].

"I would consider one [risk information] that's more tailored to the individual, instead of being given books that say 'The risk is this, the risk is that.' It's too general. Why isn't it tailored for the person who's there? Instead it's blunderbuss approach really, it's just kind of so wide" [33].

"Making a decision about what treatment to go for is a combination of belief, what you feel in your own body, and whether others have had success. That's what drives me ... if you rely on one doctor, or whoever, you only get part of the picture. In the end only you can bring all the elements necessary together to make a decision." [28] "I like seeing a doctor who is aware of the bigger picture. Even if she decides or recommends a conventional Ireatment, at least I know they're aware of alternative health thinking...that gives me more confidence in the
tre seeing a ding treatment, at least I know they're aware of alternative health thinking...that gives me
treatment, even if their treatment might end up being the same [conventional]" [29].

"I expect it [CAM] to be provided on the NHS and [to be] more widely available" [19].

"I don't think they [oncologists] were terribly encouraging. I suppose ... I know complementary medicines work, but I had this horrible thing with my diet I was doing with nuts and fruit. When I told him what I was doing all my doctor said to me was, "What do monkeys eat?" [28].

"It is just as sound as conventional medicine. It's just that there haven't been enough studies yet" [37]. "CAM needs to be looked at scientifically in order to give it the credibility that it deserves" [26].

"I went to seminars where there was a group of people that offered different thoughts about food as alternative medicine. It was very interesting and very much an education. I also read a lot and talked a lot to herbalists and naturopaths" [31]. "In the past, in [conventional] medicine, only the doctors go to lectures, to learn new cutting edge things. But we're all trying to find out what's on the cutting edge now. We're our own physicians" [29].

"I know that my disease course is unusual. If I had given away the responsibility and taken cortisone and let myself be controlled, I would have been in a totally different place.//If I hadn't taken all these alternative therapies and walked the road I have walked, I would have been in a wheelchair a long time ago//In the end we are our own teachers and masters ... I feel that I'm starting to own more of my story even though a lot is still too painful to relate to" [23]. "At least I felt I was in control and trying to do something to help myself, which made me feel better" [18]. 
Table 3 Patients' concepts of individualised medicine (Continued)

\begin{tabular}{|c|c|c|c|}
\hline & $\begin{array}{l}\text { Activation of self healing } \\
\text { power }\end{array}$ & $\begin{array}{l}\text { Activation of physiological } \\
\text { self healing }\end{array}$ & $\begin{array}{l}\text { "I think that the two basic differences in approach are: 1) attack the disease, the problem itself, or 2) support the } \\
\text { body to attack it. And those are the two different approaches. I compare the medical approach at the moment to } \\
\text { the napalm bombing of Viet Nam. I think that is the kind of mind set-we have a problem and we're going to } \\
\text { eradicate it.... What are you aiming at: Do you want to kill the cancer cell or do you want to strengthen my } \\
\text { body?" [35] }\end{array}$ \\
\hline & & Healing power of mind & $\begin{array}{l}\text { "I think your overall spiritual, psychological state has a lot to do with [disease] progression. If you believe the thing } \\
\text { is more powerful than you are or somehow able to inflict great damage, it's like pointing the bone. But if you } \\
\text { can... get the thing into perspective and say it's just a chronic thing then I think it doesn't progress as fast" [40]. } \\
\text { "I think so yeah because your mind can influence your body so I think that if you don't believe that it's going to } \\
\text { work then it won't work" [34]. }\end{array}$ \\
\hline \multirow[t]{4}{*}{ Wellbeing } & Physical wellbeing & & $\begin{array}{l}\text { "As I have had ankylosing spondylitis for over } 30 \text { years and angina for about } 7 \text { years, I do not expect to be cured. } \\
\text { But I hope that my back and pain from my frozen shoulder which I had for } 4 \text { month since my retirement at age } 65 \\
\text { will be reduced enough to enable me to enjoy my gardening and an occasional round of golf" [19]. }\end{array}$ \\
\hline & Psychological wellbeing & & $\begin{array}{l}\text { "...feeling comfortable whether it's the physical state of the room or the, the welcome of the therapist, all, all does } \\
\text { something to lower those barriers and make you feel more open and trusting" [32]. }\end{array}$ \\
\hline & $\begin{array}{l}\text { Avoidance of adverse drug } \\
\text { or treatment effects }\end{array}$ & & $\begin{array}{l}\text { "I'm sure you heard one time, 'The treatment is worse than disease,' you know, before it becomes an advanced } \\
\text { disease. All the side effects that you experienced from the Western medicine treatments. Oh, my God, can there be } \\
\text { a better way to treat?" [31] }\end{array}$ \\
\hline & $\begin{array}{l}\text { Wellbeing after emotional } \\
\text { clearing }\end{array}$ & & $\begin{array}{l}\text { "For the first time I felt like the various and seemingly disparate symptoms I was coming in with actually made } \\
\text { sense to my healthcare provider and fit within a framework that that person understood, and also within a } \\
\text { treatment model that that person understood, and then could be used to help make me better-which it is, and I } \\
\text { am" [29]. "It was sometimes really hard to get in there and break it all down to look at what I am made up of, at a } \\
\text { microscopic level. It gave me this new appreciation as to why I am the way I am and why I react the way I do. } \\
\text { Before I knew if I felt sad or scared, but never really totally explored why. Like really explored. It is a tough thing to } \\
\text { do" [27]. }\end{array}$ \\
\hline
\end{tabular}




\section{Physical wellbeing}

The dimension of maintaining physical wellbeing and functionality (i.e., being more active and continuing to work during treatment) was of great importance to patients. This dimension was related to the life limitations which an illness can cause and to patients' hope for possible improvements brought about with the support of individualised medicine $[17,19,20,26,34,43]$.

\section{Psychological wellbeing}

Patients sought a treatment environment in which they were able to relieve their tensions. CAM therapists were perceived as making a greater attempt than COM providers to individualise care so that patients could experience a relaxed, supportive environment that also attended to the purely hedonistic aspects of patient care (e.g., relaxing environment with music); also important to this experience was the provision of therapeutic CAM-based care throughout the patient encounter. Patients construed this form of individualised care as not causing stress and as being enjoyable, and as providing the opportunity for a "time out" from regular activities $[17,19,24,26,27,32,39,43-45]$.

\section{Avoidance of adverse drug or treatment effects}

This dimension of "wellbeing" denoted the wish of patients for individualised natural treatment with fewer side effects. Furthermore, patients wanted an individualised approach that included CAM treatments as a natural strategy to deal with harmful treatments and to relieve the side effects, damage and discomfort caused by conventional treatments $[17,19,22,23,26,30,34,35,39,41,43,44,46]$.

\section{Wellbeing after emotional clearing}

Some individualised healthcare modalities that triggered self-regulation were perceived by patients as being stressful at the outset, but patients expressed that they subsequently experienced a pleasing effect once they had successfully navigated this temporarily emotional exertive situation. "Wellbeing" was not synonymous with pure wellness in a hedonistic sense only, but resulted from deeper conflict solving, in a sense of personalised care $[17,18,27,29]$.

\section{Discussion}

This meta-ethnographic study used the three-stage approach of a rigorous literature search and quality appraisal, a synthesis of qualitative research and an interpretation of overarching constructs for addressing the research question as to what concepts of individualised medicine patients have who use complementary therapies. Although there exist a handful of research projects with qualitative studies that begin to investigate patients' notions of personalised medicine,
[47-49] the relative dearth of primary studies reporting on this topic required us to take the indirection with reasons for CAM use as documented in qualitative studies.

With a meta-ethnographic methodology, our synthesis could proceed from a reciprocal translation of reasons for CAM use to a higher-order interpretation in the same way that a primary study might move from a descriptive analysis to an explanatory analysis [50-53]. Meta-ethnography such as in our study can also be used for understanding and enriching the discourse on humanistic issues [15,54-56].

Other published meta-ethnographic studies differ in their methodology with regard to the steps we described above. In this project, we tried to stay as close as possible to the methods suggested by Noblit and Hare [15]; however, our procedure may add ideas and material for further clarifications in the development of the metaethnographic synthesis procedure.

As is common in qualitative research projects, a key question appeared as to when and how data saturation was achieved. We discovered that after translating twothirds of the studies, no new themes could be found; we even went so far as to extend this synthesis to the excluded studies to provide the most robust analysis possible, with the same result. Previously published reviews of specific and individual-preferences in healthcare and patients' reasons for turning to CAM report results that are somewhat comparable to those of our second-order constructs of our meta-ethnographic study [6-8]. Reasons for patients' decision to use CAM include the ability to obtain emotional support, holistic care and information from their chosen provider, as well as their perception that CAM permits patients to establish a good therapeutic relationship and cope more effectively with their medical condition(s) [7]. Other reasons include patients' beliefs that CAM provides more personal control and a greater promise of hope than conventional therapies [6]; previous research has also found that patients appreciate what they perceive as the ease-of-access of alternatives, respect for the psycho-emotional aspects of their treatment and increased consultation time associated with CAM therapies [8].

Comparing our results of the third sequence of the meta-ethnography, the interpretation of concepts of "individualised medicine"with the ideas of research and academic medicine, politics as well as economics, we found that they differ from the current concept of the genetically and biologically oriented form of "personalised or individualised medicine". Presently, there exists no commonly accepted definition of this form of "individualised medicine"; the lowest common denominator is actually the "division of patients (groups) by biomarkers" [4]. This contrasts considerably with the 
richness of humanistic issues associated with the concepts of "individualised medicine" concepts that we identified in patients reasons for seeking CAM. One dissenting aspect is the concept of "personal growth", an effectiveness dimension which describes patients hope to be empowered by the healthcare encounter in individualised medicine. In contrast to the concepts of biomarkers and individual disease risks, the concept of the inner growth as induced by a reassessment of disease and life history can include growth in spirituality, body awareness and appreciation of nature and surroundings. In this dimension, patients request an individualised form of medicine that takes into consideration their wish for "personal growth", including emotional disease handling. Successfully adapting to an illness or to reassess their biography in this way can enable patients to participate in social activities and feel healthy despite their physical limitations [57]. Meditation or mindfully presence in a given situation, and, consequently, the provision of such practices, can help in the search for meaning in life [58].

As an example a person-centred approach in fibromyalgia syndrome (FMS) patients of "respectfully recognizing the patients' personal and human needs," "encouraging the patients' self-revelation," "let[ting] the patient tell their story" and "digesting emotions to [patients'] illness and life situations" helped patients to identify how suffering might fit into their individual psychosocial contexts. In particular, there was a need to help patients understand how suffering might fit into family dynamics and how associated psychosocial conditions might be ameliorated [49]. Medical and therapeutic practitioners could thus be asked to support patients in their endeavour to lead a meaningful life in spite of their disease and might be urged to bear in mind that patients need therapeutic and social support to discover their resources in the personal, biographical or spiritual environment to undertake a development of inner or "personal growth" [59].

The person-centred approach in FMS noted above coincides with to the dimensions of "emotional disease handling," "biographical reassessment" and "transformation" of our meta-synthesis in the "personal growth" concept. Moreover, in the biomedical model, diverse symptoms of diseases such as FMS are often addressed separately from their interconnectedness and linkages to the patient's individualised bio-psychosocial factors [49]. Likewise, our concept of "personal growth" is strongly interrelated with that of "holism", which the patients in our meta-synthesis associated with "individualised medicine". For the patients it is important not to regard health problems in isolation; rather, they should be considered in conjunction [60]. A holistic or integrative view requires that psychological and physical treatment interdependences must work together in order to be successful [60]. In opposition to the concept of "holism", the treatment based on individual biomarker-based stratification and genome-based information does not reflect the patients' need to connect the disease with bio-psychosocial factors.

Also of note is that from our meta-ethnographic study it is apparent that patients like to assume responsibility for their care and that they have a wish for "personal autonomy", which may come about via "educational empowerment" and/or "active control". This is also manifested in patients' desire for knowledge-building in matters of their disease. The wish of patients for "self-activation" is also related to triggering intrinsic self-healing capacities by supporting the immune system and mental health resources, as expressed in the subtheme of "activation of self-healing power".

In contrast, the genome-based individualised healthcare that is becoming more prominent in today's traditional medical fields connects patients' own activity more with extrinsic factors by avoiding genetic or metabolic risks. In the patients' view of individualized medicine with regard to "self-activation", CAM was perceived by patients as allowing for "individual responsibility for health" [61]. Also, according to Kienle et al. (2011), patients seek CAM therapies with the aim to support and stimulate autoprotective and (auto-)salutogenic potentials, mostly with the active cooperation of the patient or of his/her body [62]. Healthcare providers must consider patients' own experience and own body knowledge as important information. The salutogenic potential as "enabling the patient to swim" stands for the mobilisation of individual resources for more autonomy [42,62], which can be comparably expressed as the dimension of "personal autonomy" in our meta-ethnography results. The determination of individual disease risks as one goal of genome-based individualised medicine with its preliminary fixing to a possible disease does not consider the mobilisation of individual biological, psychosocial and spiritual resources.

Interestingly, as reflected in our study, a portion of what is normally called the placebo effect may be attributed to the "activation of self-healing power,"-a fact often neglected and not considered in the concept of disease risk determination. Another dimension of "personal autonomy," namely, "educational empowerment" is a reason for the appeal of complementary medicine [63]. Lay people suffer from the circumstance that detailed technological advances in medicine have prohibited them from acquiring knowledge about their medical diagnosis [63]. Researchers potentially investigate and collect results of individuals' biomarker-based stratification and genome-based health-related characteristics only. The knowledge and actions required for maintaining health may be controlled by persons other than individual patients who, in contrast, want to be 
empowered for their own health [64], as expressed in patients' stated desire for "activation of self-healing power".

"Self-activation" coincides here with the third-order concept of "alliance", which reflects the subthemes of "time" and "healing relationship" in the context of the doctor-patient-interaction. These subthemes are often referred to by patients as core features for individualised care and as motivation to visit CAM providers. Thus, it should be ensured that "speaking medicine" (i.e., doctorpatient interaction), which includes the time a physician needs for detailed information and guidance is sufficiently covered by insurers and other medical health-payment systems.

Other studies show also that a patient-centred communication style of COM physicians is rated as "very important" by patients [65] and the provision of sufficient information and shared decision-making options are top patient priorities [66]. Another example, this one of personalised health care for patients with spinal cord injury, demonstrated that when a closer relationship with staff was formed, the healthcare professionals became an essential support factor; this study also found that providing patients with explicit information of patients about their condition and prognosis was necessary for their accepting the realities of their injury [48].

Consultations that last longer are perceived as being associated with a patient-centred communication style, or as a "doctor's interest in you as a person" [48,65,66], enabling patients to realise "educational empowerment" as expressed through the concept of "self-activation". In the view of genome-based individualised medicine, it could be debated whether the idea of a commercially available determination of risk factors through genetic diagnostic measurements empowers the individuals to seek more knowledge about their own genomes, in turn enabling them to encourage their doctors to also consider this information. The effective use of such diagnostic tools could empower patients to work with their healthcare providers to determine the most suitable prevention or treatment plan [67].

Furthermore, the findings from our meta-ethnographic study show that patients perceive medicine as highly individualised and personalised when they are able to connect different treatment options according to their own personal preferences; this is expressed in our thirdorder concept of "integrative care". Here, this concept is associated with the "alliance" concept and the subtheme of establishing a "healing relationship". "Healing relationship" stands also for shared decision making in treatment agendas integrating COM and CAM. The process of shared decision making is currently the most discussed way to take into account individual preferences. However it must be noted, that complementary treatment options are still neglected in the development of decision aids
[68], although patients prefer to integrate CAM into their "tailored care" to manage their individual medical conditions [69]. Again, in this context the link between "individualised medicine" and "integrative care" can be detected [1]. One of the greatest skills of a doctor is individualisation, including subtle changes to therapy and how this therapy is delivered by a skilled healthcare provider. This influences the subjective patient's response. A therapist who tailors his treatment will have better patients' outcomes because she or he can more effectively embrace the meaning of the therapeutic response [70]. Over and above that, "integrative care", including both CAM and conventional therapies for chronic diseases, could have the potential to improve a costly and fragmented delivery system [47].

On the other hand "tailored care" can coincide with gene-based risk information or tests that are customised to personal biological characteristics. Genome-based diagnostic measurements - and, consequently accurate diagnosis, specific treatments and adjusted medication doses - correlate closely with patients' perspective of "tailored care". However, there is a need for comprehensible information on the results of such measurements and the meaning of the diagnosis; patients need physicians to provide a medical explanation for lay people. With educational support, patients even prefer to calculate and interpret event rates and the number needed to treat or to harm [71]. We argue that gene-based risk information must therefore be accompanied by the concept of "educational empowerment". A central dimension of "educational empowerment" is the provision of evidence based patient information which enables patients to judge and to decide according to their own preferences [71,72].

The final third-order concept of individualised medicine "wellbeing" as discussed in our study is often mentioned in the included literature as the desire for both psychological and physical "wellbeing". Patients expressed a strong desire for individualised care provided in a familiar environment. When such care was not available, patients found it difficult to meet even basic physical needs [73]. A more familiar and less clinically medicalised environment is thus reflected as individualised care [48]. Patients seek CAM therapies as comparatively harmless ways to support the body's healing capabilities [70,74]. The patients in our synthesised studies also sought support for the sometimes difficult work of emotional self-regulation in the dimension of "wellbeing after emotional clearing".

The provision of functional ability is regarded as a fundamental part of "physical wellbeing". Here, the biomolecular concepts of differential interventions offers effective treatment and the reduction of side effects as well as unique therapeutic items (e.g., prostheses, implants adapted as a truly individual), those enable patients to continue engaging in normal activities in a sense of 
"wellbeing". Moreover, regarding the desire for fewer side effects, patients' expectations merge with the goals of genome-based individualised medicine in the search for an exact diagnosis and targeted treatment. It could be debated that the introduction of pharmacogenomic concepts into the practice of herbal medicine could be effective in reducing incidences of CAM-associated therapy failures. Furthermore, the phenomenon of psychosocial genomics, which explores the sophisticated relationship between gene expression, neurogenesis and healing practices, has the potential to reconcile biomedicine with various healing experiences brought about CAM [75].

In summary, the patients described in the included qualitative studies have a humanistic concept of "individualised" medicine that entails much more than individualised specifications on the molecular level, such as is the case in genome-based "personalised medicine". Similar to the above-discussed patients' concepts of "individualised medicine", the German Bundestag's report on the future of individualised medicine reflects our finding that the patients may have other preferences (e.g., emotional dimension, handling of the disease) than the genome-based concepts [3]. In addition, a clear distinction has been defined, namely that "individual medicine does not have any contribution for disease handling and the particular psychological burden which the probabilistic-predictive information of the individual medicine implies" [3]. With this statement, the report's authors referred to the need that "individualised medicine" should be embedded in the context of "speaking medicine" (i.e., doctors-patient interaction) and psychosocial support [3].

Furthermore, in May 2012, a number of German experts discussed at the annual meeting of the German Ethics Council the expansion/addition of biologically targeted "individualised medicine" to psychological, social, biographical and spiritual aspects. In a joint effort of such medical research and care, the patient would benefit from - rather than being a victim - of progress [76].

\section{Study limitations}

All of the studies included in our meta-ethnographic study investigated patients who used CAM as a complement to COM. We also included studies with focus groups interviewing non-CAM users being asked about their perception of CAM. The patients of the identified studies were mostly COM users in the beginning of their disease who turned to CAM for the reasons discussed above. Therefore, the investigated patient samples seem to be well balanced and can be interpreted as representing the "usual" patient population, as far as this is possible in such a qualitative approach. However, it must be emphasized that patients who turn to CAM modalities are more likely to seek out a healthy lifestyle or preventive measures than non-CAM users [77].

We must also consider that some of the concepts discussed in this study may overestimate patients' individual perspectives as compared to the whole patient population. However, as the general trend towards more complementary and integrative health care is increasingly acknowledged as an expression of what is felt to be missing in COM, healthcare providers and decision makers should take these needs seriously as they seek to develop a modern concept of individualised medicine compatible with patients' needs.

\section{Conclusions}

Based on the results of our meta-ethnographic study, it can be stated that there exists a difference between the concept of individualisation from the patient perspective and the present notion of "personalised or individualised medicine" on the basis of genetics and biology. Patients' core expectations for individualised care are a respect for "personal growth", a "holistic" focus, a doctorpatient-"alliance", "self-activation", "integrative care" and "wellbeing". There is a congruence of patients' expectations with the goals of genome-based individualised medicine in the search for a reduction of side effects and functional ability, which would in turn enable patients to continue engaging in normal activities. In addition, detailed diagnostic measurements and consequently suited treatments, as well as adjusted medication doses correlated closely with patients' perspective of "tailored care". Furthermore, patients' knowledge of genomic risk factors could be reflected their concept of "educational empowerment".

At present, alternative other patient ideas related to individualised medicine are rarely reflected in genomebased individualisation concepts. At the individual level of patient perceptions, the concepts of individualised and integrated medicine merge. For these reasons, a comprehensive concept of "individualised and integrative health care" could be formed to include both the genome-based perspective of individualised medicine and the more holistic perspective of individualisation frequently expressed by patients. Such a comprehensive approach to medicine would provide patients the opportunity to share their commitment to "personal growth" with their healthcare provider, as well as a "holistic" view and a willingness to engage in "self-activation" with "educational empowerment"; this approach could be characterized by a doctor-patient "alliance" in the sense of "time" and the "healing relationship" and the freedom of "integrative care" and "wellbeing" through fewer side effects and increased functional ability. When allocating funds for research and health budgets, patients' notions with regard to individual treatment should play an 
important role in the pursuit of a high-quality healthcare system.

\section{Additional files}

\section{Additional file 1: PRISMA 2009 Checklist. \\ Additional file 2: PRISMA 2009 Flow Diagram.}

\section{Competing interests}

The authors declare that they have no competing interests.

\section{Authors' contributions}

All authors contributed to the development of the manuscript. All authors read and approved the final manuscript.

\section{Acknowledgements}

We are grateful to the contribution of the quality research colloquium of the chair of Medical Theory, Integrative and Anthroposophic Medicine at University Witten/Herdecke for providing helpful advice and comments on the quality appraisal of the included studies.

Received: 14 October 2012 Accepted: 2 May 2013

Published: 3 June 2013

\section{References}

1. Heusser P, Neugebauer E, Berger B, Hahn E: Integrative and Personalized Health Care - Requirements for a Timely Health-Care System. Gesundheitswesen 2013, 75(3):151-154.

2. Gesundheitsforschungsprogramm.pdf: http://www.gesundheitsforschungbmbf.de/_media/Gesundheitsforschungsprogramm.pdf] date of access: 2011 Nov 22.

3. Hüsing B, Hartig J, Bührlen B, Reiß T, Gaisser S: TAB-Arbeitsbericht-ab126. pdf. http://www.pmstiftung.eu/fileadmin/dokumente/Buecher_Blogs/TABArbeitsbericht-ab126.pdf] date of access: 2011 Nov 22.

4. Hüsing B: Individualised medicine - potentials and need for action. Z Evid Fortbild Qual Gesundhwes 2010, 104(10):727-731.

5. Müller-Jung J: Integrative Medizin Vom Gebot zur alternativen Heilkunst. FAZ. NET; 2011. http://www.faz.net/aktuell/wissen/medizin/integrative-medizinvom-gebot-zur-alternativen-heilkunst-11489819.html] date of access: 2012 Sep 23.

6. Verhoef MJ, Balneaves LG, Boon HS, Vroegindewey A: Reasons for and characteristics associated with complementary and alternative medicine use among adult cancer patients: a systematic review. Integr Cancer Ther 2005, 4(4):274-286.

7. Ernst E, Hung SK: Great Expectations. Patient 2011, 4:89-101.

8. Köntopp S: Wer nutzt Komplementärmedizin? PhD thesis. Essen: KVC Verlag; 2004.

9. Barbour RS: Checklists for improving rigour in qualitative research: a case of the tail wagging the dog? BMJ 2001, 322(7294):1115-1117.

10. Reis S, Hermoni D, Van-Raalte R, Dahan R, Borkan JM: Aggregation of qualitative studies-From theory to practice: Patient priorities and family medicine/general practice evaluations. Patient Educ Couns 2007, 65(2):214-222

11. Giacomini MK, Cook DJ: Users' guides to the medical literature: XXIII. Qualitative research in health care A. Are the results of the study valid? Evidence-Based Medicine Working Group. JAMA 2000, 284(3):357-362.

12. Broom A: Using qualitative interviews in CAM research: a guide to study design, data collection and data analysis. Complement Ther Med 2005, 13(1):65-73.

13. Kania A, Porcino A, Vehoef MJ: Value of qualitative research in the study of massage therapy. Int J Ther Massage Bodywork 2008, 1(2):6-10.

14. Ritenbaugh C, Nichter M, Nichter MA, Kelly KL, Sims CM, Bell IR, Castañeda HM, Elder CR, Koithan MS, Sutherland EG, Verhoef MJ, Warber SL, Coons S. Developing a patient-centered outcome measure for complementary and alternative medicine therapies I: defining content and format. BMC Complement Altern Med 2011, 11:135.

15. Noblit GW, Hare RD: Meta-Ethnography: Synthesizing Qualitative Studies. Newbury Park: Sage Publications, Incorporated; 1988.
16. White $M$, Verhoef $M$ : Cancer as part of the journey: the role of spirituality in the decision to decline conventional prostate cancer treatment and to use complementary and alternative medicine. Integr Cancer Ther 2006, 5(2):117-122.

17. Evans MA, Shaw ARG, Sharp DJ, Thompson EA, Falk S, Turton P, Thompson $\mathrm{T}$ : Men with cancer: is their use of complementary and alternative medicine a response to needs unmet by conventional care? Eur $J$ Cancer Care (Engl) 2007, 16(6):517-525.

18. Nichol J, Thompson EA, Shaw A: Beliefs, decision-making, and dialogue about complementary and alternative medicine (CAM) within families using CAM: a qualitative study. J Altern Complement Med 2011, 17(2):117-125.

19. Richardson J: What patients expect from complementary therapy: a qualitative study. Am J Public Health 2004, 94(6):1049-1053.

20. Grace S, Higgs J: Integrative medicine: enhancing quality in primary health care. J Altern Complement Med 2010, 16(9):945-950.

21. Shaw A, Thompson EA, Sharp D: Complementary therapy use by patients and parents of children with asthma and the implications for NHS care: a qualitative study. BMC Health Serv Res 2006, 6:76.

22. La Cour P: Rheumatic disease and complementary-alternative treatments: a qualitative study of patient's experiences. I Clin Rheumatol 2008, 14(6):332-337.

23. Salamonsen A, Launsø L, Kruse TE, Eriksen SH: Understanding unexpected courses of multiple sclerosis among patients using complementary and alternative medicine: A travel from recipient to explorer. Int I Qual Stud Health Well-being 2010, 5:2.

24. Conboy L, Quilty MT, Kerr C, Shaw J, Wayne P: A qualitative analysis of adolescents' experiences of active and sham Japanese-style acupuncture protocols administered in a clinical trial. J Altern Complement Med 2008, 14(6):699-705.

25. Adler SR, Wrubel J, Hughes E, Beinfield H: Patients' Interactions With Physicians and Complementary and Alternative Medicine Practitioners: Older Women With Breast Cancer and Self-Managed Health Care. Integr Cancer Ther 2009, 8(1):63-70.

26. Ribeiro MA, Harrigan RC: The use of Complementary and Alternative Medicine by Asian women of Hawai'i in the treatment of breast cancer. Hawaii Med J 2006, 65(7):198-205.

27. Mulkins AL, Verhoef MJ: Supporting the transformative process: experiences of cancer patients receiving integrative care. Integr Cancer Ther 2004, 3(3):230-237.

28. Broom A: Intuition, subjectivity, and Le bricoleur: cancer patients' accounts of negotiating a plurality of therapeutic options. Qual Health Res 2009, 19(8):1050-1059.

29. McCaffrey AM, Pugh GF, O'Connor BB: Understanding patient preference for integrative medical care: results from patient focus groups. J Gen Intern Med 2007, 22(11):1500-1505.

30. Canales MK, Geller BM: Surviving breast cancer: the role of complementary therapies. Fam Community Health 2003, 26(1):11-24.

31. Wanchai A, Armer JM, Stewart BR: Breast cancer survivors' perspectives of care practices in Western and alternative medicine. Oncol Nurs Forum 2010, 37(4):494-500.

32. Smith JM, Sullivan SJ, Baxter GD: The culture of massage therapy: valued elements and the role of comfort, contact, connection and caring. Complement Ther Med 2009, 17(4):181-189.

33. Walter FM, Emery JD, Rogers M, Britten N: Women's views of optimal risk communication and decision making in general practice consultations about the menopause and hormone replacement therapy. Patient Educ Couns 2004, 53(2):121-128.

34. Patterson C, Arthur H, Noesgaard C, Caldwell P, Vohra J, Francoeur C, Swinton M: Exploring adolescent complementary/alternative medicine (CAM) use in Canada. J Interprof Care 2008, 22(1):45-55.

35. Boon H, Brown JB, Gavin A, Kennard MA, Stewart M: Breast cancer survivors' perceptions of complementary/alternative medicine (CAM): making the decision to use or not to use. Qual Health Res 1999, 9(5):639-653.

36. Jones RA, Taylor AG, Bourguignon C, Steeves R, Fraser G, Lippert M, Theodorescu D, Mathews H, Kilbridge KL: Complementary and alternative medicine modality use and beliefs among African American prostate cancer survivors. Oncol Nurs Forum 2007, 34(2):359-364.

37. Barrett B, Marchand L, Scheder J, Plane MB, Maberry R, Appelbaum D, Rake $D$, Rabago D: Themes of holism, empowerment, access, and legitimacy 
define complementary, alternative, and integrative medicine in relation to conventional biomedicine. J Altern Complement Med 2003, 9(6):937-947.

38. Steinsbekk A, Launsø L: Empowering the cancer patient or controlling the tumor? A qualitative study of how cancer patients experience consultations with complementary and alternative medicine practitioners and physicians, respectively. Integr Cancer Ther 2005, 4(2):195-200.

39. Humpel N, Jones SC: Gaining insight into the what, why and where of complementary and alternative medicine use by cancer patients and survivors. Eur J Cancer Care (Engl) 2006, 15(4):362-368.

40. McDonald K, Slavin S: My body, my life, my choice: practices and meanings of complementary and alternative medicine among a sample of Australian people living with HIV/AIDS and their practitioners. AIDS Care 2010, 22(10):1229-1235.

41. Singh $H$, Maskarinec $G$, Shumay DM: Understanding the motivation for conventional and complementary/alternative medicine use among men with prostate cancer. Integr Cancer Ther 2005, 4(2):187-194.

42. Antonovsky A: Salutogenese: zur Entmystifizierung der Gesundheit. Tübingen: Dgvt-Verl; 1997.

43. Correa-Velez I, Clavarino A, Eastwood H: Surviving, relieving, repairing, and boosting up: reasons for using complementary/alternative medicine among patients with advanced cancer: a thematic analysis. $J$ Palliat Med 2005, 8(5):953-961.

44. Foote-Ardah CE: The meaning of complementary and alternative medicine practices among people with HIV in the United States: strategies for managing everyday life. Sociol Health IIIn 2003, 25(5):481-500

45. Richmond JA, Bailey DE Jr, McHutchison JG, Muir AJ: The use of mind-body medicine and prayer among adult patients with chronic hepatitis $C$. Gastroenterol Nurs 2010, 33(3):210-216.

46. Chen W-T, Shiu C-S, Simoni J, Fredriksen-Goldsen K, Zhang F, Starks H, Zhao $H$ : Attitudes toward antiretroviral therapy and complementary and alternative medicine in Chinese patients infected with HIV. J Assoc Nurses AIDS Care 2009, 20(3):203-217.

47. Westrom KK, Maiers MJ, Evans RL, Bronfort G: Individualized chiropractic and integrative care for low back pain: the design of a randomized clinical trial using a mixed-methods approach. Trials 2010, 11:24.

48. Garrino L, Curto N, Decorte R, Felisi N, Matta E, Gregorino S, Actis MV, Marchisio C, Carone R: Towards personalized care for persons with spinal cord injury: a study on patients' perceptions. J Spinal Cord Med 2011, 34(1):67-75

49. Masi AT, White KP, Pilcher JJ: Person-centered approach to care, teaching, and research in fibromyalgia syndrome: justification from biopsychosocial perspectives in populations. Semin Arthritis Rheum 2002, 32(2):71-93.

50. Gallacher K, Bhautesh J, Deborah M, Sara M, David B, Patricia E, MC R, MV M, T ED, Fiona S, David BG, MF S: Qualitative systematic reviews of treatment burden in stroke, heart failure and diabetes - Methodological challenges and solutions. BMC Med Res Methodol 2013, 13(1):10

51. Greenhalgh T, Robert G, Macfarlane F, Bate P, Kyriakidou O, Peacock R: Storylines of research in diffusion of innovation: a meta-narrative approach to systematic review. Soc Sci Med 2005, 61(2):417-430.

52. Barnett-Page $\mathrm{E}$, Thomas J: Methods for the synthesis of qualitative research: a critical review. BMC Med Res Methodol 2009, 9:59.

53. Atkins S, Lewin S, Smith H, Engel M, Fretheim A, Volmink J: Conducting a meta-ethnography of qualitative literature: lessons learnt. BMC Med Res Methodol 2008, 8:21.

54. Wikberg A, Bondas T: A patient perspective in research on intercultural caring in maternity care: A meta-ethnography. Int J Qual Stud Health Wellbeing 2010, 5: doi:10.3402/qhw.v5i1.4648.

55. Mclnnes L: To synthesise or not synthesise? That is the question! Worldviews Evid Based Nurs 2005, 2(2):49-51.

56. Mays N, Pope C, Popay J: Systematically reviewing qualitative and quantitative evidence to inform management and policy-making in the health field. J Health Serv Res Policy 2005, 10(1):6-20.

57. Huber M, Knottnerus JA, Green L, Van der Horst H, Jadad AR, Kromhout D, Leonard B, Lorig K, Loureiro MI, Van der Meer JWM, Schnabel P, Smith R, Van Weel C, Smid H: How should we define health? BMJ 2011, 343:d4163.

58. Musial F, Büssing A, Heusser P, Choi K-E, Ostermann T: Mindfulness-based stress reduction for integrative cancer care: a summary of evidence. Forsch Komplementmed 2011, 18(4):192-202.
59. Kalitzkus $V$, Matthiessen PF: Personal growth in chronic illness - a biographical case study of living with fibromyalgia. Forsch Komplementmed 2010, 17(4):203-208.

60. Stamer M, Müller VE, Berger B, Schmacke N: Perspektiven von Patientinnen und Patienten auf ihre Versorgung durch homöopathisch tätige Ärzte und Ärztinnen - Eine qualitative Studie. Abschlussbericht. Bremen. 2010. http://www.akg.uni-bremen.de/pages/arbeitspapierBeschreibung.php?ID = 28\&SPRACHE = DE] date of access: 2011 Nov 16

61. McClean S: "The illness is part of the person": discourses of blame, individual responsibility and individuation at a centre for spiritual healing in the North of England. Sociol Health IIIn 2005, 27(5):628-648.

62. Kienle GS, Albonico H-U, Fischer L, Frei-Erb M, Hamre HJ, Heusser P, Matthiessen PF, Renfer A, Kiene H: Complementary Therapy Systems and Their Integrative Evaluation. EXPLORE. The Journal of Science and Healing 2011, 7:175-187

63. Lyng S: Holistic Health and Biomedical Medicine - A Countersystem Analysis. SUNY Series in the Political Economy of Health Care. Albany: State University of New York Press; 1990.

64. Bischof M: Salutogenese - Unterwegs zur Gesundheit. Neue Gesundheitskonzepte und die Entfaltung einer Integrativen Medizin. Drachen Verlag: Klein Jasedow; 2010.

65. Swenson SL, Buell S, Zettler P, White M, Ruston DC, Lo B: Patient-centered communication: do patients really prefer it? J Gen Intern Med 2004, 19(11):1069-1079.

66. Schattner A, Bronstein A, Jellin N: Information and shared decision-making are top patients' priorities. BMC Health Serv Res 2006, 6:21.

67. Chua EW, Kennedy MA: Current State and Future Prospects of Direct-to -Consumer Pharmacogenetics. Front Pharmacol 2012, 3:152.

68. Berger S, Braehler E, Ernst J: The health professional-patient-relationship in conventional versus complementary and alternative medicine. A qualitative study comparing the perceived use of medical shared decision-making between two different approaches of medicine. Patient Educ Couns 2012, 88(1):129-137.

69. Brien SB, Bishop FL, Riggs K, Stevenson D, Freire V, Lewith G: Integrated medicine in the management of chronic illness: a qualitative study. $\mathrm{Br} J$ Gen Pract 2011, 61(583):e89-e96.

70. Walach $\mathrm{H}$, Jonas WB: Placebo research: the evidence base for harnessing self-healing capacities. J Altern Complement Med 2004, 10(Suppl 1):S103-S112

71. Berger B, Steckelberg A, Meyer G, Kasper J, Mühlhauser I: Training of patient and consumer representatives in the basic competencies of evidence-based medicine: a feasibility study. BMC Med Educ 2010, 10:16.

72. Müller V, Schmacke N, Kolip P, Berger B: Desirable, unfamiliar and in need of communication - the evidence-based decision aid of the Institute for Quality and Efficiency in Health Care (IQWiG)]. Z Evid Fortbild Qual Gesundhwes 2012, 106(4):290-294

73. Humber N, Dickinson P: Rural patients' experiences accessing surgery in British Columbia. Can J Surg 2010, 53(6):373-378.

74. Joos S, Glassen K, Musselmann B: Herbal Medicine in Primary Healthcare in Germany: The Patient's Perspective. Evid Based Complement Alternat Med 2012, 2012:294638.

75. Oguamanam C: Personalized medicine and complementary and alternative medicine: in search of common grounds. J Altern Complement Med 2009, 15(8):943-949.

76. Deutscher Ethikrat: Deutscher Ethikrat: Personalisierte Medizin - der Patient als Nutznießer oder Opfer? Simultanmitschrift. 2012. http://www.ethikrat.org/ veranstaltungen/jahrestagungen/personalisierte-medizin] date of access: 2013 Jan 15

77. George M, Campbell J, Rand C: Self-management of acute asthma among low-income urban adults. J Asthma 2009, 46(6):618-624.

doi:10.1186/1472-6882-13-124

Cite this article as: Franzel et al:: Individualised medicine from the perspectives of patients using complementary therapies: a metaethnography approach. BMC Complementary and Alternative Medicine 2013 13:124. 